\title{
Genetic risk for Alzheimer's disease, cognition and Mild Behavioral Impairment in healthy older adults
}

Byron Creese*, PhD, Medical School, College of Medicine and Health, University of Exeter, UK

Helen Brooker, BSc, Medical School, College of Medicine and Health, University of Exeter, UK

Dag Aarsland, MD, Department of Old Age Psychiatry, Institute of Psychiatry, Psychology and Neuroscience, King's College London, UK

Anne Corbett, PhD, Medical School, College of Medicine and Health, University of Exeter, UK

Clive Ballard, MD, Medical School, College of Medicine and Health, University of Exeter, UK Zahinoor Ismail, MD, Departments of Psychiatry, Clinical Neurosciences, and Community Health Sciences, Hotchkiss Brain Institute and O'Brien Institute for Public Health, University of Calgary, Calgary, Alberta, Canada; Medical School, College of Medicine and Health, University of Exeter, UK

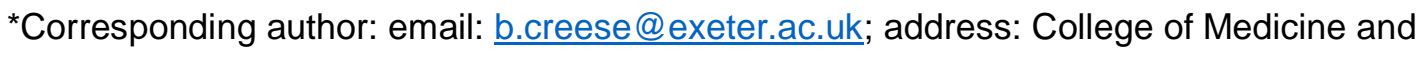
Health, University of Exeter, RILD Building, Barrack Road, Exeter, EX2 5AX, UK

Key words: Mild Behavioral Impairment, dementia, neuropsychiatric symptoms, polygenic score, Alzheimer's disease, cognition

Abbreviations: MBI (Mild Behavioral Impairment); NPS (neuropsychiatric symptoms); PRS (polygenic risk score); IQCODE (Informant Questionnaire on Cognitive Decline in the Elderly); IADL (instrumental activities of daily living)

Word count: 3678 


\section{Abstract}

BACKGROUND: Mild Behavioral Impairment $(\mathrm{MBI})$ is a neuropsychiatric syndrome describing later-life emergent apathy, mood/anxiety symptoms, impulse dyscontrol, social inappropriateness and psychosis that are not attributable to psychiatric diagnoses. $\mathrm{MBI}$ is an at-risk state for incident cognitive decline and dementia, and is associated with dementia biomarkers including $A \beta$ and neurofilament light. Thus, MBI may be an early clinical marker of neurodegenerative disease. In this study, we hypothesized that stratification by MBI in a cognitively normal sample would moderate the signal between Alzheimer's disease (AD) genetic risk and cognition.

METHODS: Genetic, cognitive and MBI data was available for 3,126 PROTECT study participants over 50 without dementia. A general cognitive composite score was constructed based on scores on paired associates learning, digit span, self-ordered search and verbal reasoning. $\mathrm{MBI}$ was assessed using the $\mathrm{MBI}$ Checklist. Polygenic scores for $A D$ were split by tertile (representing low, medium and high risk) and the sample was stratified by MBI into those with no symptoms and those with any symptoms.

RESULTS: AD genetic risk was associated with poorer cognition in the MBI strata only (MBI: $F(2,1746)=4.95, p=0.007 ;$ no $\mathrm{MBI}: F(2,1366)=0.72, p=0.49)$. The mean difference between low and high genetic risk groups was significant $(p=0.005)$ and the standardised effect size in the $\mathrm{MBI}$ sample was higher than in the whole sample.

CONCLUSIONS: These findings justify MBI screening to enrich samples with at-risk individuals, and underscore the importance of late-life neuropsychiatric symptoms in cognitive ageing. 
medRxiv preprint doi: https://doi.org/10.1101/2020.05.13.20100800; this version posted May 16, 2020. The copyright holder for this preprint (which was not certified by peer review) is the author/funder, who has granted medRxiv a license to display the preprint in perpetuity.

It is made available under a CC-BY-NC-ND 4.0 International license .

\section{Background}

Worldwide, the number of people with dementia is expected to rise to 150 million by 2050 . Recent years have been marked by a number of high profile failures of disease modifying therapies and it is now widely recognised that identification of people in the very earliest stages of dementia is a key priority for clinical trials of new treatments, and ultimately for clinical practice [1]. Genetic predictors of cognitive decline and dementia have been the subject of considerable focus in recent years. These predictors include not only apolipoprotein E (APOE) status but also polygenic risk scores (PRS). PRS are the sum of $A D$ risk alleles carried by an individual weighted by effect size, and therefore capture more genetic risk than APOE alone. The ultimate goal of this work is the identification of low cost early marker of neurodegenerative disease. As an important first step, numerous studies have shown that $A D$ genomic markers predict $A D$ and mild cognitive impairment $(\mathrm{MCl})$ case/control status, as well as progression to $\mathrm{AD}$ among $\mathrm{MCl}$ cases [2-7]. However, the association between $A D$ genetic risk and objectively measured cognition in non-dementia samples is less consistent. Although at least nine studies have examined this question, four have reported a no link [8-15]. There are a number of methodological differences which likely explain these discrepancies, including the sensitivity of cognitive outcome measures and the number of risk alleles included in PRS calculation. One additional challenge is the complex etiology of cognition in older adults, which is not solely accounted for by genetic risk for neurodegeneration or neuropsychological profile. Because of the ease and low cost of genetic analysis, and promising initial findings, it is logical to explore strategies that may enhance sensitivity.

One study found that stratification based on $A \beta$ positive positron emission tomography (PET) scans unmasked an association between AD PRS and poorer memory and executive function [12]. That neuropathological markers of $A D$ moderate the association between $A D$ 
medRxiv preprint doi: https://doi.org/10.1101/2020.05.13.20100800; this version posted May 16, 2020. The copyright holder for this preprint

genetic risk and neuropsychological measures is not surprising, but does offer proof of principle of sample enrichment, informing our study. In order to add value to a genetic screen, such sample enrichment should be low cost and scalable to large populations. Scalability is not achievable with PET imaging due to cost and barriers to access, but there is evidence that later-life emergent neuropsychiatric symptoms (NPS), described by the validated syndrome, Mild Behavioral Impairment (MBI), may represent such a screening tool. $\mathrm{MBI}$ is a neurobehavioral syndrome proposed by an Alzheimer's Association consensus group to describe a risk state for cognitive decline and dementia in order to facilitate earlier dementia detection [16]. The MBI syndrome covers late-life emergent apathy, mood/anxiety symptoms, impulse dyscontrol, social inappropriateness, and psychotic symptoms, and is common and easily measured in the general population [17]. Moreover, $\mathrm{MBI}$ is associated with progressive cognitive decline in individuals without significant cognitive impairment and a shorter time to dementia in individuals with normal cognition or $\mathrm{MCl}$ at baseline [18-22]. Crucially, MBI has recently been shown to associate with known dementia biomarkers. In a sample of cognitively normal older adults, MBI score was associated with a greater burden of PET amyloid, suggesting it is a novel neuropsychiatric marker of preclinical disease [23]. In a sample of non-demented older adults with normal cognition and $\mathrm{MCl}, \mathrm{MBI}$ was associated with faster accumulation of neurofilament light, which is a marker of axonal loss, and there is preliminary evidence that $\mathrm{MBI}$ is associated with AD PRS [24,25]. On the basis of this evidence linking $\mathrm{MBI}$ to the neurobiology of dementia, $\mathrm{MBI}$ is an attractive candidate tool to enrich samples with individuals at greater risk of dementia. To examine this application of $\mathrm{MBI}$, we tested whether the relationship between $\mathrm{AD}$ genetic risk and cognition was moderated by $\mathrm{MBI}$ symptoms in a cohort of older adults without dementia. We hypothesised $A D$ genetic risk would be associated with poorer cognition and that this relationship would be strongest among people with $\mathrm{MBI}$ symptoms.

\section{Method}


medRxiv preprint doi: https://doi.org/10.1101/2020.05.13.20100800; this version posted May 16, 2020. The copyright holder for this preprint (which was not certified by peer review) is the author/funder, who has granted medRxiv a license to display the preprint in perpetuity.

It is made available under a CC-BY-NC-ND 4.0 International license .

\section{Participants}

Data from 4,591 participants taking part in the Platform for Research Online to Investigate Genetics and Cognition in Aging (PROTECT) study were analysed in this study (REC reference 13/LO/1578). Written informed consent was obtained from all participants and proxy informants. PROTECT is a UK-based online participant registry which tracks the cognitive health of older adults. Inclusion criteria for enrolling in PROTECT are 1) >=50 years old; 2) no diagnosis of dementia; and 3) access to a computer and internet. This sample is a subset of PROETCT study participants who also provided a saliva sample for genotyping, completed cognitive testing and had a proxy informant available to complete the $\mathrm{MBI}$ Checklist (MBI-C, further detail is presented below).

\section{Assessment of Cognition}

Cognitive performance was assessed via a battery of four tests (Table 1). Individual performance across cognitive tests is known to be correlated, and for this study we analysed a general cognitive composite based on factor analysis of the battery. This latent construct, capturing general cognitive ability, is a well-documented feature of cognition [26]. To capture general cognitive ability in this sample, a composite score was calculated by computing the first unrotated principal component of the cognitive battery. The variance in total cognitive test score explained by the first principal component was $48.4 \%$ and the factor loadings were 0.53 (paired associated learning), 0.5 (digit span), 0.46 (self-ordered search) and 0.51 (verbal reasoning). This finding is comparable to recent reports in an analysis of over 300,000 individuals across multiple cohorts [27]. In the present study, lower cognitive composite score was associated higher Informant Questionnaire on Cognitive Decline in the Elderly (IQCODE) score, which indicates a negative change in cognition over 10 years via a 
medRxiv preprint doi: https://doi.org/10.1101/2020.05.13.20100800; this version posted May 16, 2020. The copyright holder for this preprint (which was not certified by peer review) is the author/funder, who has granted medRxiv a license to display the preprint in perpetuity.

It is made available under a CC-BY-NC-ND 4.0 International license .

questionnaire observed by a proxy informant $\left(\beta[S E]=-0.16[0.04], p=2.72 \times 10^{-5}\right)$, and greater impairment in instrumental activities of daily living (IADL) as measured by the Minimum Data Set-Home Care IADL scale $\left(\beta[S E]=-0.23[0.04], p=1.09 \times 10^{-9}\right)$, providing validation that the cognitive construct is meaningful in the context of our sample $[28,29]$.

Table 1: Description of the cognitive battery used

\begin{tabular}{|c|c|c|}
\hline Test & Description & Cognitive domain \\
\hline $\begin{array}{l}\text { Paired } \\
\text { associates } \\
\text { learning }\end{array}$ & $\begin{array}{l}\text { A series of objects appear in the cells on screen. The } \\
\text { participant is instructed to remember the cell in which } \\
\text { the object appears. When an object appears at the } \\
\text { bottom centre, the participant is instructed to click on } \\
\text { the cell in which they recall seeing that object. }\end{array}$ & $\begin{array}{l}\text { Visual working } \\
\text { memory, learning }\end{array}$ \\
\hline Digit span & $\begin{array}{l}\text { Using a ratchet-style approach in which each } \\
\text { successful trial is followed by a new sequence that is } \\
1 \text { digit longer than the last and each unsuccessful } \\
\text { trial is followed by a new sequence that is } 1 \text { digit } \\
\text { shorter than the last. }\end{array}$ & Working memory \\
\hline $\begin{array}{l}\text { Self-ordered } \\
\text { search }\end{array}$ & $\begin{array}{l}\text { A series of boxes are present on the screen, one of } \\
\text { the boxes will contain a diamond. The participant } \\
\text { selects each box until they locate the diamond. The } \\
\text { diamond is then placed in another box and again the } \\
\text { participant must locate it, but they must be careful } \\
\text { not to select the box in which the diamond was } \\
\text { previously found. }\end{array}$ & $\begin{array}{l}\text { Executive function, } \\
\text { spatial working } \\
\text { memory }\end{array}$ \\
\hline $\begin{array}{l}\text { Verbal } \\
\text { reasoning }\end{array}$ & $\begin{array}{l}\text { A sentence is displayed at the bottom of the screen } \\
\text { whilst a square and a circle are displayed above. The } \\
\text { participant needs to respond true or false as to } \\
\text { whether the sentence correctly describes the } \\
\text { configuration of the circle and square. }\end{array}$ & Verbal reasoning \\
\hline
\end{tabular}

Assessment of neuropsychiatric symptoms

Neuropsychiatric symptoms were operationalized in the $\mathrm{MBI}$ framework using the $\mathrm{MBI}$ Checklist (MBI-C). The MBI-C is a validated tool designed specifically for capturing MBI symptoms and, in this study, was completed by a proxy informant who knew the participant well for at least 10 years [17,30-32]. The scale consists of 34 questions covering the full range of $\mathrm{MBI}$ domains (apathy, mood/anxiety symptoms, impulse dyscontrol, social 
medRxiv preprint doi: https://doi.org/10.1101/2020.05.13.20100800; this version posted May 16, 2020. The copyright holder for this preprint

inappropriateness, and psychotic symptoms). Each question is rated on a scale of 0 (not present) to 3 (severe). The MBI-C mandates that a symptom must be present for at least 6 months and represent a change from longstanding behaviour in order to be rated as present. This approach facilitates differentiation of $\mathrm{MBI}$ symptoms from transient neuropsychiatric symptoms and reactive conditions due to medical and environmental precipitants, in order to better reflect the new onset symptomatology seen in neurodegenerative disease [33]. In this study participants were classified as having any symptoms of $\mathrm{MBI}(\mathrm{MBI}-\mathrm{C}$ total score $>0)$ or having no $\mathrm{MBI}$ symptoms (MBI-C total score=0) due to the strong positive skew of the MBI-C data (i.e. $~ 50 \%$ of respondents can be expected to score zero) [17]. Any participants with the following medical conditions were excluded (all derived from self-report responses to the question "Have you ever been diagnosed with one or more of the following even if you don't have it currently?": mild cognitive impairment $(n=70)$, stroke $(n=375)$, Parkinson's disease $(n=47)$, depression $(n=592)$, mania/bipolar/manic depression $(n=152)$, anxiety/generalized anxiety disorder $(n=12)$, panic attacks $(n=3)$, anorexia nervosa $(n=135)$, bulimia nervosa $(n=14)$, psychological overeating/binge eating $(n=1)$, autism/Asperger's/autistic spectrum disorder $(n=1)$, attention deficit disorder $(n=1)$. The questionnaire also covered schizophrenia/other psychotic illnesses, personality disorders and social anxiety/phobia but no participants reported having these. We also excluded anyone who scored $>=13$ on the Patient Health Questionnaire 9 (PHQ9), indicating a probably current major depressive episode $(n=253)$. These exclusions were applied in order to reflect the Alzheimer's Association MBI diagnostic criteria stipulation that symptoms cannot be better explained by a pre-existing medical or psychiatric condition [16]; 1,463 individual participants met at least one of these exclusion criteria.

The binary coding of the MBI-C is supported by recent data showing that in cognitively normal people, a score $>0$ on the MBI-C (i.e. the presence of any symptoms of any severity) 
medRxiv preprint doi: https://doi.org/10.1101/2020.05.13.20100800; this version posted May 16, 2020. The copyright holder for this preprint (which was not certified by peer review) is the author/funder, who has granted medRxiv a license to display the preprint in perpetuity.

It is made available under a CC-BY-NC-ND 4.0 International license .

was associated with worse cognitive performance (both at baseline and over one year) on a range of tests, with a score of $>8$ being associated with the worst performance [19].

\section{Genetic data $Q C$ and $A D$ polygenic risk score calculation}

Using PLINK, SNP and individual quality control exclusions were applied to genotype data (minor allele frequency (MAF) $\leq 1 \%$, Hardy Weinberg equilibrium $p<10^{-5}$, SNP and individual missingness $>2 \%$, mean heterozygosity $\pm 3 S D$, chip-gender mismatches, non-European ancestry (derived from genetic principal components calculated in PLINK and projected onto HapMap phase 3 populations, see Supplementary Material), related/duplicate (pi-hat $>0.2$ ) samples). Phasing (EAGLE2) and imputation (PBWT) was done via the Sanger Imputation Service using the Haplotype Reference Consortium (r1.1) reference panel. SNPs with imputation quality (INFO) score $\geq 0.8$ and MAF $\geq 0.01$ were retained, leaving $6,782,377$ available for analysis. IGAP AD GWAS was used to calculate PRS using PRSice (clumped using $250 \mathrm{~kb}$ windows and $\left.\mathrm{r}^{2}>0.1\right)[34,35]$. Previous data suggests a wide range of inclusion thresholds for PRS calculation, from only GWAS significant SNPs to many thousands of SNPs [2,3,8-15]. In this study, we opted for two AD GWAS SNP inclusion thresholds $\left(P_{T}\right)$. The first, $1 \times 10^{-5}$ (93 SNPS), was chosen because it was the most strongly associated with a family history of dementia $\left(\beta=0.07, \mathrm{SE}=0.01, \mathrm{p}=4.54 \times 10^{-13}\right)$ in the PROTECT study and the second was all IGAP SNPs (i.e. $P_{T=1}$ ). AD PRS at $P_{T=1}$ was also associated with family history status $(\beta=0.02, S E=0.01, p=0.01)$. PRS without the APOE locus (chr19:44,00,000$46,500,000)$ were also calculated.

\section{Statistical analysis}


medRxiv preprint doi: https://doi.org/10.1101/2020.05.13.20100800; this version posted May 16, 2020. The copyright holder for this preprint

PRS were standardized before analysis. PRS were split by tertile with the bottom $1 / 3$ representing low $A D$ genetic risk, the middle 1/3 medium genetic risk and the top 1/3 high genetic risk. The cognitive composite score was normalised for age, sex and education using a linear regression models and the standardised residuals used in subsequent analysis. The association between $A D$ genetic risk and cognition was first tested by ANCOVA in the whole sample at both $P_{T}$. The sample was then stratified by MBI status and the dependent variable of cognitive composite was analysed by ANCOVA with AD genetic risk group (three level factor) and the first four ancestry principal components as covariates. The effect size for the overall ANCOVA was expressed by partial eta-squared $\left(\eta^{2}\right)$. Tukey post-hoc test was used to undertake planned pairwise comparisons between levels of $A D$ genetic risk, and effect sizes for mean differences between these groups were expressed by Cohen's $d$. ANCOVA assumptions were checked by examining residual plots and checking for outliers. Given that the two AD PRS are not independent, and a Bonferroni correction would therefore be overly conservative, a family-wise error rate of 0.025 was applied (to reflect tests on the two $\mathrm{MBI}$ symptom groups). Post-hoc comparisons between the three $\mathrm{AD}$ genetic risk groups were Bonferroni adjusted. All statistical analysis was performed in R.

\section{Results}

\section{Participant characteristics}

Following medical and psychiatric history exclusions, 3,126 participants were available for analysis. Participant characteristics by cognitive group are shown in Table 2. There was no difference in age, sex or education level between the $\mathrm{MBI}$ and no $\mathrm{MBI}$ strata (age: $\mathrm{t}=0.41$, $d f=3034.4, p=0.68$; sex: $X=0.035, d f=1, p=0.85$; education level: $X=6.65, d f=5, p=0.25$ ) but, 
as expected, the MBI group did have a lower cognitive score $(t=2.87, d f=2948.1, p=0.004$, Cohen's $d=0.1$ ).

Table 2: Participant characteristics by cognitive group

\begin{tabular}{|c|c|c|c|c|c|}
\hline \multirow[b]{3}{*}{$\mathbf{N}(\%)$} & \multicolumn{4}{|c|}{ MBI strata } & \multirow[t]{2}{*}{$\mathbf{P}$} \\
\hline & \multicolumn{2}{|c|}{ No Symptoms (MBI-C=0) } & \multicolumn{2}{|c|}{$\begin{array}{l}\text { MBI Symptoms (MBI- } \\
\text { C>0) }\end{array}$} & \\
\hline & 1373 & 44 & 1753 & 56 & \\
\hline Age (mean, sd) & 63.6 & 6.5 & 63.5 & 7.03 & $0.68^{*}$ \\
\hline \multicolumn{6}{|l|}{$\operatorname{Sex}(n, \%)$} \\
\hline Male & 314 & 23 & 407 & 23 & $0.85^{\dagger}$ \\
\hline Female & 1059 & 77 & 1346 & 77 & \\
\hline \multicolumn{6}{|l|}{ Education level (n, \%) } \\
\hline Secondary education & 149 & 11 & 227 & 13 & $0.65^{\dagger}$ \\
\hline Post-secondary education & 146 & 11 & 208 & 12 & \\
\hline Vocational qualification & 270 & 20 & 326 & 19 & \\
\hline Undergraduate degree & 508 & 37 & 605 & 35 & \\
\hline Post graduate degree & 235 & 17 & 315 & 18 & \\
\hline Doctoral degree & 65 & 5 & 72 & 4 & \\
\hline $\begin{array}{l}\text { Cognitive composite (mean, } \\
\text { sd) }\end{array}$ & 0.26 & 1.2 & 0.14 & 1.18 & $0.004^{*}$ \\
\hline \multicolumn{6}{|c|}{$\begin{array}{l}\text { Abbreviations: MBI, Mild Behavioral Impairment; MBI-C, Mild Behavioral Impairment Checklist; } \\
\text { sd, Standard Deviation } \\
\text { p-value of t-test } \\
\text { tp-value of chi-square test }\end{array}$} \\
\hline
\end{tabular}

$\underline{\text { Relationship between AD PRS, cognition and neuropsychiatric symptoms }}$

In the whole sample analysis, $\mathrm{AD}$ genetic risk at $P_{T=1}$ was associated with a lower mean cognitive composite score $\left(F(2,3119)=3.93, p=0.02\right.$, partial $\left.\eta^{2}=0.003\right)$ but not at the more conservative PRS at $P_{T=1 \times 10^{-5}}(\mathrm{~F}(2,3119)=1.11, \mathrm{p}=0.33)$. Pairwise comparisons showed that the mean difference in cognitive score for the high genetic risk and low genetic risk groups was statistically significant but there were no differences between the other groups 
(mean difference: $-0.15, p=0.02$, Cohen's $d=0.13$, Table 3 ). Linear regression using the untransformed AD PRS (i.e. as a normally distributed continuous level variable rather than tertiles) produced a similar result $\left(\beta[S E]=-0.05[0.02], \mathrm{p}=0.03\right.$, with analysis at $P_{T=1 \times 10^{-5}}$ remaining non-significant). Accordingly, the rest of the analysis was only conducted on $A D$ PRS at $P_{T=1}$.

In stratified analysis, shown in Table 3 and Figure 1, the association between AD genetic risk and cognition persisted but only in those with $\mathrm{MBI}$ symptoms, where the effect size was larger than in the whole sample analysis $\left(F(2,1746)=4.95, p=0.007\right.$, partial $\left.\eta^{2}=0.006\right)$. In those with no $\mathrm{MBI}$ symptoms there was no association between $A D$ genetic risk and cognition $(F(2,1366)=0.72, p=0.49)$. Pairwise comparisons in the $\mathrm{MBI}$ symptom sample showed that mean difference in cognitive scores between the high and low genetic risk groups was again statistically significant, with a larger effect size than in the whole sample analysis, Cohen's $d$ increased from 0.13 to 0.19 (mean difference: $-0.22, p=0.005$ ). The association remained statistically significant after removing the APOE locus, although the effect size was attenuated $\left(F(2,1746)=3.23, p=0.04\right.$, partial $\eta^{2}=0.002$; mean difference between high and low genetic risk groups: $-0.17, p=0.03$, Cohen's $d=0.14$ ). 
medRxiv preprint doi: https://doi.org/10.1101/2020.05.13.20100800; this version posted May 16, 2020. The copyright holder for this preprint (which was not certified by peer review) is the author/funder, who has granted medRxiv a license to display the preprint in perpetuity.

It is made available under a CC-BY-NC-ND 4.0 International license .

Figure 1: Plot of adjusted mean cognitive composite score by AD genetic risk group $\left(P_{T=1}\right)$ stratified by $\mathrm{MBI}$ symptom grouping.

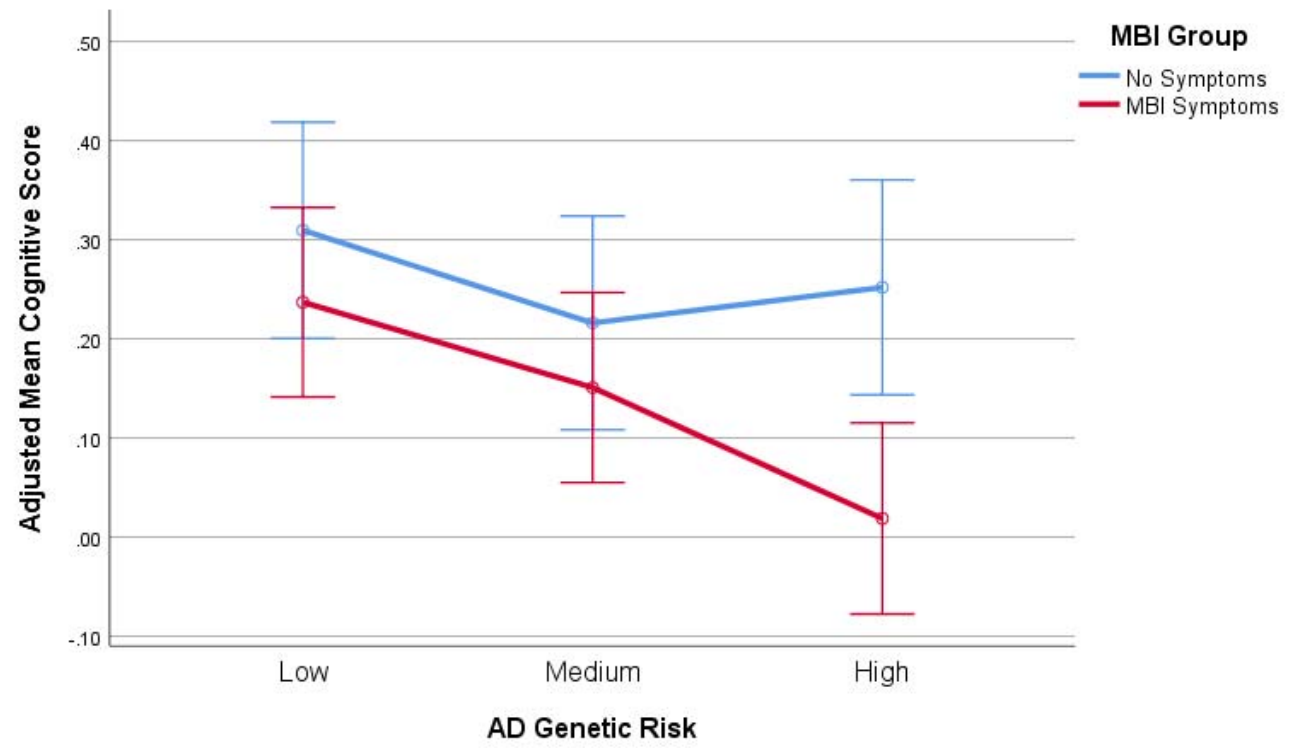

Error bars: $95 \% \mathrm{Cl}$

Abbreviations: MBI, Mild Behavioral Impairment 
Table 3: Mean differences in cognitive scores by AD genetic risk group stratified by MBI symptoms

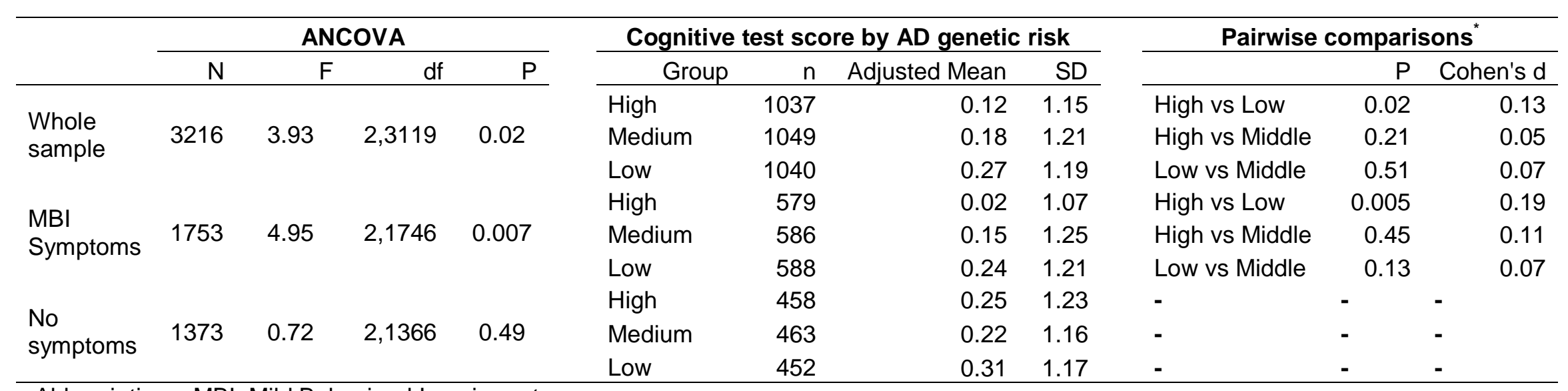

Abbreviations: MBI, Mild Behavioral Impairment.

"Post-hoc pairwise comparison computed by Tukey test ( $p$-values are Bonferroni adjusted).

-: pairwise comparisons not undertaken as ANCOVA was not significant. 
Sensitivity analysis

In our primary analysis we adopted a binary coding for MBI symptoms (none vs. any) because of evidence that even individuals with low level symptoms have an increased risk of cognitive decline. There are no accepted cut points on the MBI-C in cognitively normal community samples so, post-hoc, we examined the association between AD PRS, cognitive impairment and $\mathrm{MBI}$ using an $\mathrm{MBI}-\mathrm{C}$ cut point of $\geq 3$. For context, this means that the $\mathrm{MBI}$ group now contained any individual who had experienced at least one 'severely' rated symptom or multiple less severe symptoms, while the no $\mathrm{MBI}$ group contained all other participants; this resulted in 2,020 in the no symptoms group and 1,106 in the MBI group. The associations observed in the main analysis were sustained with a similar effect size (MBI symptoms: $F(1,1099)=3.01, p=0.048$, partial $\eta^{2}=0.005 ; \quad$ No symptoms: $F(1,2013)=1.79, p=0.17)$ and the magnitude of the differences between the high and low genetic risk groups in the $\mathrm{MBI}$ symptom sample was the same (mean difference: -0.20 , $p=0.047$, Cohen's $d=0.19$ ).

\section{Discussion}

To our knowledge, these findings are the first demonstration that sample stratification on neuropsychiatric symptoms (here assessed in the MBI framework) enhances the effect size of the association between $A D$ genetic risk and cognition in a sample of cognitively normal older adults. The association was present in our study using a PRS based on all available SNPs from AD GWAS $\left(P_{T=1}\right)$ and remained after exclusion of the APOE locus, albeit at a diminished effect size. Taken together we conclude that APOE is driving much of the signal observed in this study, consistent with previous reports, but that non-APOE SNPs also play a role in late life cognition. More broadly, our findings from this sample, which is 
medRxiv preprint doi: https://doi.org/10.1101/2020.05.13.20100800; this version posted May 16, 2020. The copyright holder for this preprint

independent from previous reports, support a role for AD genetic risk, beyond APOE, in cognition among older adults without dementia, an important finding as there is not unanimity in previous literature [8-11,13-15].

A recent well phenotyped large study of older adults found that AD PRS which included all SNPs $\left(P_{T}=1\right)$ was not associated with cognition in adults but APOE was [14]. Genetic risk for AD, including APOE and other SNPs, has been shown to be pleiotropic but it is notable that a previous study found the effect of APOE on cognition to be stronger in older adults relative to earlier in life $[36,37]$. Older samples will likely contain a larger number of individuals in prodromal or preclinical disease so a stronger effect could be reasonably expected for this reason. Similarly, we propose that stratifying on $\mathrm{MBI}$, even among cognitively normal older adults, has the same effect and defines a cognitive phenotype which is 'closer' to Alzheimer's disease. This in turn would create better power to detect associations with those AD SNPs with smaller effect sizes, thus explaining the discrepancy between our finding and this other recent work.

The notion that neuropsychiatric symptoms (i.e. MBI) may be an early marker of dementia is somewhat counterintuitive for a group of diseases that are primarily conceptualised as cognitive disorders. This cognocentric approach does not necessarily reflect the history of AD. Auguste D., the index patient described by Alois Alzheimer presented to hospital with emotional dysregulation and suspiciousness, followed by cognitive decline [33,38-40]. Several longitudinal studies support MBI emerging in advance of cognitive symptoms or increasing risk of incident cognitive decline and dementia [18,20,21,41]. The distinction between $\mathrm{MBI}$ and other neuropsychiatric symptoms as risk factors vs. early markers has been a topic of recent debate $[42,43]$. However, new data in cognitively normal people showing that $\mathrm{MBI}$ symptoms are associated with higher amyloid beta burden [23] and faster 
medRxiv preprint doi: https://doi.org/10.1101/2020.05.13.20100800; this version posted May 16, 2020. The copyright holder for this preprint

accumulation of neurofilament light [24] support the view of $\mathrm{MBI}$ as an early clinical marker. The implication is therefore that stratification on $\mathrm{MBI}$ symptoms enriches samples for individuals with preclinical or prodromal disease, creating a more etiologically homogenous sample. Deeper phenotyping including fluid imaging and longitudinal follow up with detailed neuropsychology and clinical outcomes will be required to confirm this hypothesis, which could have important implications for clinical trials where cohort heterogeneity has been identified as a major concern [44].

The operationalization of $\mathrm{MBI}$ is worth some discussion. A key strength of this study is the exclusion of pre-existing psychiatric conditions and use of the specific MBI-C tool, both of which provide more confidence that our findings are due to later-life emergent mild NPS rather than longstanding clinically significant psychiatric diagnoses. However, establishing appropriate cut points on the $\mathrm{MBI}-\mathrm{C}$ is a matter of ongoing research. Our findings, including our post-hoc analysis, suggest that relatively mild symptoms are important to consider and that the likely optimal cut point on the MBI-C would lie somewhere between 2 and 8 . This is supported by previous research in showing that low level symptoms of MBI as well as the more severe symptoms are associated with cognitive decline in cognitively healthy individuals [19]. Relating to this, a limitation to our study is the proxy completion of MBI-C via remote questionnaire completion, which could have led to some misclassifications, although raters in this study were required to know the participant for at least 10 years. Other limitations include the over representation of women and more highly educated people in our sample and, as with most genetic studies, these results may not be generalizable to non-European ancestry populations. We note our sample size is relatively small compared with much of the wider genetic literature and replication in independent cohorts is needed. At present we are not aware of any other large cohort studies which use the MBI-C, however we would argue that our findings, along with the practical advantages of the MBI-C (it is 
freely available and quick to complete) provide a strong case the wider adoption of the scale which will allow important follow up work to take place.

\section{Conclusions}

In summary, this study lends further support to the growing evidence base that later life emergent neuropsychiatric symptoms describe an at-risk state for incident cognitive decline and dementia, and can be the index manifestation of dementia for some, associated with dementia biomarkers and genetic risk. Our findings also support the case for using $\mathrm{MBI}$ as a sample enrichment tool for biomarker studies and clinical trials targeting at-risk individuals. The enrichment approach is inexpensive, simple, and scalable, and can decrease cost and improve enrolment efficiency of dementia clinical trials [45]. Deeper phenotyping of these groups including neuroimaging and longitudinal monitoring of clinical outcomes is now essential.

\section{Additional files}

File name: Supplementary Material

File format: MS word .docx

Description: figures showing ancestry principal components

\section{Declarations}

\section{Ethics approval and consent to participate}


Ethical approval for the PROTECT study itself was obtained from the London Bridge Research Ethics Committee (reference 13/LO/1578). Written informed consent was obtained from all participants and proxy informants, this consent also covers secondary analysis of data by third party approval researchers so separate approval was not required for this analysis.

\section{Consent for publication}

Not applicable.

\section{Availability of data and materials}

The data that support the findings of this study are available from support.protect@exeter.ac.uk but restrictions apply to the availability of these data, which were used under license for the current study, and so are not publicly available. Data are however available from the authors upon reasonable request and with permission of the PROTECT study.

\section{Competing interests}

Clive Ballard has received contract grant funding from ACADIA, Lundbeck, Takeda, and Axovant pharmaceutical companies and honoraria from Lundbeck, Lilly, Otsuka, and Orion pharmaceutical companies. Dag Aarsland has received research support and/or honoraria from Astra-Zeneca, H. Lundbeck, Novartis Pharmaceuticals, and GE Health, and serves as a paid consultant for $\mathrm{H}$. Lundbeck and Axovant. Zahinoor Ismail has received honoraria/consulting fees from Janssen, Lundbeck, Otsuka, and Sunovion, although not related to this work.

\section{Funding}

This work was funded in part through the MRC Proximity to Discovery: Industry Engagement Fund (External Collaboration, Innovation and Entrepreneurism: Translational Medicine in Exeter 2 (EXCITEME2) ref. MC_PC_17189) awarded to Dr Creese. The addition of the 
family history of dementia questionnaire to the PROTECT study was supported by a small grant from the Alzheimer's Research UK South West Network. This paper represents independent research part funded by the National Institute for Health Research (NIHR) Biomedical Research Centre at South London and Maudsley NHS Foundation Trust and King's College London. None of the funding bodies had any role in the design, analysis or interpretation of data, or the drafting of the manuscript.

\section{$\underline{\text { Authors' contributions }}$}

BC: conceptualisation, analysis design, statistical analysis, interpretation of findings and manuscript drafting; ZI: conceptualisation, analysis design, interpretation of findings and manuscript drafting; CB: analysis design, interpretation of findings and manuscript drafting; HB: data acquisition, manuscript review; AC: data acquisition, manuscript review, funding; DA: data acquisition, manuscript review.

\section{$\underline{\text { Acknowledgements }}$}

This research was also supported by the NIHR Collaboration for Leadership in Applied Health Research and Care South West Peninsula. The views expressed are those of the author(s) and not necessarily those of the NHS, the NIHR or the Department of Health and Social Care. The authors thank Gemma Shireby at University of Exeter for providing the analysis script for genetic ancestry check. Genotyping was performed at deCODE Genetics. 
medRxiv preprint doi: https://doi.org/10.1101/2020.05.13.20100800; this version posted May 16, 2020. The copyright holder for this preprint (which was not certified by peer review) is the author/funder, who has granted medRxiv a license to display the preprint in perpetuity.

It is made available under a CC-BY-NC-ND 4.0 International license .

\section{References}

1. Cummings J, Lee G, Ritter A, Sabbagh M, Zhong K. Alzheimer's disease drug development pipeline: 2019. Alzheimer’s Dement Transl Res Clin Interv [Internet]. 2019;5:272-93. Available from:

http://www.sciencedirect.com/science/article/pii/S2352873719300290

2. Escott-Price V, Sims R, Bannister C, Harold D, Vronskaya M, Majounie E, et al. Common polygenic variation enhances risk prediction for Alzheimer's disease. Brain [Internet]. 2015;138:3673-84. Available from: https://doi.org/10.1093/brain/awv268

3. Chaudhury S, Brookes KJ, Patel T, Fallows A, Guetta-Baranes T, Turton JC, et al. Alzheimer's disease polygenic risk score as a predictor of conversion from mild-cognitive impairment. TransI Psychiatry [Internet]. 2019;9:154. Available from:

https://doi.org/10.1038/s41398-019-0485-7

4. Logue MW, Panizzon MS, Elman JA, Gillespie NA, Hatton SN, Gustavson DE, et al. Use of an Alzheimer's disease polygenic risk score to identify mild cognitive impairment in adults in their 50s. Mol Psychiatry [Internet]. 2019;24:421-30. Available from:

https://doi.org/10.1038/s41380-018-0030-8

5. Lacour A, Espinosa A, Louwersheimer E, Heilmann S, Hernández I, Wolfsgruber S, et al. Genome-wide significant risk factors for Alzheimer's disease: role in progression to dementia due to Alzheimer's disease among subjects with mild cognitive impairment. Mol Psychiatry [Internet]. 2017;22:153-60. Available from: https://doi.org/10.1038/mp.2016.18

6. Desikan RS, Fan CC, Wang Y, Schork AJ, Cabral HJ, Cupples LA, et al. Genetic assessment of age-associated Alzheimer disease risk: Development and validation of a polygenic hazard score. PLOS Med [Internet]. 2017;14:e1002258. Available from: https://doi.org/10.1371/journal.pmed.1002258

7. Adams HHH, de Bruijn RFAG, Hofman A, Uitterlinden AG, van Duijn CM, Vernooij MW, et 
medRxiv preprint doi: https://doi.org/10.1101/2020.05.13.20100800; this version posted May 16, 2020. The copyright holder for this preprint (which was not certified by peer review) is the author/funder, who has granted medRxiv a license to display the preprint in perpetuity.

It is made available under a CC-BY-NC-ND 4.0 International license .

al. Genetic risk of neurodegenerative diseases is associated with mild cognitive impairment and conversion to dementia. Alzheimer's Dement [Internet]. 2015;11:1277-85. Available from: http://www.sciencedirect.com/science/article/pii/S1552526015001181

8. Harris SE, Davies G, Luciano M, Payton A, Fox HC, Haggarty P, et al. Polygenic risk for Alzheimer's disease is not associated with cognitive ability or cognitive aging in nondemented older people. J Alzheimers Dis. 2013/11/20. Medical Genetics Section, University of Edinburgh Centre for Genomics and Experimental Medicine and MRC Institute of Genetics and Molecular Medicine, Western General Hospital, Crewe Road, Edinburgh, UK Centre for Cognitive Ageing and Cognitive Epidemiolog; 2014;39:565-74.

9. Darst BF, Koscik RL, Racine AM, Oh JM, Krause RA, Carlsson CM, et al. PathwaySpecific Polygenic Risk Scores as Predictors of Amyloid-beta Deposition and Cognitive Function in a Sample at Increased Risk for Alzheimer's Disease. J Alzheimers Dis. 2016/09/24. University of Wisconsin, Madison, WI, USA. Department of Population Health Sciences, University of Wisconsin School of Medicine and Public Health, Madison, WI, USA. Wisconsin Alzheimer's Institute, University of Wisconsin School of Medicine and Public Hea; 2017;55:473-84.

10. Marden JR, Mayeda ER, Walter S, Vivot A, Tchetgen Tchetgen EJ, Kawachi I, et al. Using an Alzheimer Disease Polygenic Risk Score to Predict Memory Decline in Black and White Americans Over 14 Years of Follow-up. Alzheimer Dis Assoc Disord [Internet]. 2016;30:195-202. Available from: https://www.ncbi.nlm.nih.gov/pubmed/26756387 https://www.ncbi.nlm.nih.gov/pmc/articles/PMC4940299/

11. Mormino EC, Sperling RA, Holmes AJ, Buckner RL, De Jager PL, Smoller JW, et al. Polygenic risk of Alzheimer disease is associated with early- and late-life processes. Neurology [Internet]. 2016;87:481. Available from: http://n.neurology.org/content/87/5/481.abstract

12. Ge T, Sabuncu MR, Smoller JW, Sperling RA, Mormino EC. Dissociable influences of 
medRxiv preprint doi: https://doi.org/10.1101/2020.05.13.20100800; this version posted May 16, 2020. The copyright holder for this preprint (which was not certified by peer review) is the author/funder, who has granted medRxiv a license to display the preprint in perpetuity.

It is made available under a CC-BY-NC-ND 4.0 International license .

APOE epsilon4 and polygenic risk of AD dementia on amyloid and cognition. Neurology. 2018/03/30. From the Psychiatric and Neurodevelopmental Genetics Unit (T.G., J.W.S.), Center for Genomic Medicine, Massachusetts General Hospital; Departments of Psychiatry (T.G., J.W.S.) and Neurology (R.A.S.), Massachusetts General Hospital, Harvard Medical School,; 2018;90:e1605-12.

13. Stephan Y, Sutin AR, Luchetti M, Caille P, Terracciano A. Polygenic Score for Alzheimer Disease and cognition: The mediating role of personality. J Psychiatr Res [Internet]. 2018;107:110-3. Available from:

http://www.sciencedirect.com/science/article/pii/S0022395618307003

14. Ritchie SJ, Hill WD, Marioni RE, Davies G, Hagenaars SP, Harris SE, et al. Polygenic predictors of age-related decline in cognitive ability. Mol Psychiatry [Internet]. 2019;

Available from: https://doi.org/10.1038/s41380-019-0372-x

15. Marioni RE, Campbell A, Hagenaars SP, Nagy R, Amador C, Hayward C, et al. Genetic Stratification to Identify Risk Groups for Alzheimer's Disease. J Alzheimers Dis. 2017/02/23.

Centre for Cognitive Ageing and Cognitive Epidemiology, University of Edinburgh, Edinburgh, UK. Medical Genetics Section, Centre for Genomic and Experimental Medicine, Institute of Genetics and Molecular Medicine, University of Edinburgh, Edinburgh, UK. I; 2017;57:275-83.

16. Ismail Z, Smith EE, Geda Y, Sultzer D, Brodaty H, Smith G, et al. Neuropsychiatric symptoms as early manifestations of emergent dementia: Provisional diagnostic criteria for mild behavioral impairment. Alzheimers Dement. 2015/06/23. Department of Psychiatry, University of Calgary, Calgary, Alberta, Canada; Department of Clinical Neurosciences, University of Calgary, Calgary, Alberta, Canada; Mathison Centre for Mental Health Research \& Education, University of Calgary, Calgary, Alber; 2016;12:195-202.

17. Creese B, Griffiths A, Brooker H, Corbett A, Aarsland D, Ballard C, et al. Profile of Mild Behavioral Impairment and Factor Structure of the Mild Behavioral Impairment Checklist in 
medRxiv preprint doi: https://doi.org/10.1101/2020.05.13.20100800; this version posted May 16, 2020. The copyright holder for this preprint (which was not certified by peer review) is the author/funder, who has granted medRxiv a license to display the preprint in perpetuity.

It is made available under a CC-BY-NC-ND 4.0 International license .

Cognitively Normal Older Adults. Int Psychogeriatrics. 2019;

18. Matsuoka T, Ismail Z, Narumoto J. Prevalence of Mild Behavioral Impairment and Risk of Dementia in a Psychiatric Outpatient Clinic. J Alzheimers Dis. 2019/06/10. Department of Psychiatry, Graduate School of Medical Science, Kyoto Prefectural University of Medicine, Kyoto, Japan. Departments of Psychiatry, Clinical Neurosciences, and Community Health Sciences, Hotchkiss Brain Institute and O’Brien Institute for Pub; 2019;70:505-13.

19. Creese B, Brooker H, Ismail Z, Wesnes KA, Hampshire A, Khan Z, et al. Mild Behavioral Impairment as a Marker of Cognitive Decline in Cognitively Normal Older Adults. Am J Geriatr Psychiatry. 2019;27.

20. Taragano FE, Allegri RF, Krupitzki H, Sarasola D, Serrano CM, Loñ L, et al. Mild behavioral impairment and risk of dementia. J Clin Psychiatry [Internet]. 2009;70:584-92.

Available from: http://www.ncbi.nlm.nih.gov/pmc/articles/PMC2711522/

21. Taragano FE, Allegri RF, Heisecke SL, Martelli MI, Feldman ML, Sanchez V, et al. Risk of Conversion to Dementia in a Mild Behavioral Impairment Group Compared to a Psychiatric Group and to a Mild Cognitive Impairment Group. J Alzheimers Dis. 2018/02/15. National Scientific Research Council - CONICET, Buenos Aires, Argentina. Neuropsychiatry Research Unit, CEMIC University Hospital, Galvan, Buenos Aires, Argentina.; 2018;62:22738.

22. Ismail Z, Hu S, Gill S, Forkert ND, Smith EE. SUBJECTIVE COGNITIVE DECLINE (SCD) AND MILD BEHAVIORAL IMPAIRMENT (MBI) TOGETHER PREDICT MILD COGNITIVE IMPAIRMENT AT 3 YEARS BETTER THAN EITHER SYNDROME ALONE.

Alzheimer's Dement J Alzheimer's Assoc [Internet]. 2019;15:P1535-6. Available from: https://doi.org/10.1016/j.jalz.2019.08.113

23. Lussier FZ, Pascoal TA, Chamoun M, Therriault J, Tissot C, Savard M, et al. Mild behavioral impairment is associated with $\beta$-amyloid but not tau or neurodegeneration in cognitively intact elderly individuals. Alzheimer's Dement [Internet]. 2020;16:192-9. 
medRxiv preprint doi: https://doi.org/10.1101/2020.05.13.20100800; this version posted May 16, 2020. The copyright holder for this preprint (which was not certified by peer review) is the author/funder, who has granted medRxiv a license to display the preprint in perpetuity.

It is made available under a CC-BY-NC-ND 4.0 International license .

Available from: https://alz-journals.onlinelibrary.wiley.com/doi/abs/10.1002/alz.12007

24. Ismail Z, Naude J, Gill S, Hu S, McGirr A, Forkert N, et al. Plasma Neurofilament Light: a marker of cognitive decline in Mild Behavioural Impairment. 12th Clin Trials Alzheimer's Dis Conf . San Diego, USA; 2019.

25. Andrews SJ, Ismail Z, Anstey KJ, Mortby M. Association of Alzheimer's genetic loci with mild behavioral impairment. Am J Med Genet B Neuropsychiatr Genet. 2018/11/01.

Department of Neuroscience, Icahn School of Medicine at Mount Sinai, New York, New York. Centre for Research on Ageing, Health and Wellbeing, Australian National University, Canberra, Australian Capital Territory, Australia. Department of Psychiatry, Math; 2018;177:727-35.

26. Harris SE, Deary IJ. The genetics of cognitive ability and cognitive ageing in healthy older people. Trends Cogn Sci. 2011/08/16. Centre for Cognitive Ageing and Cognitive Epidemiology, Medical Genetics Section, University of Edinburgh, Edinburgh, EH4 2XU, UK.; 2011;15:388-94.

27. Davies G, Lam M, Harris SE, Trampush JW, Luciano M, Hill WD, et al. Study of 300,486 individuals identifies 148 independent genetic loci influencing general cognitive function. Nat Commun [Internet]. 2018;9:2098. Available from: https://doi.org/10.1038/s41467-018-04362$\mathrm{X}$

28. Jorm AF. A short form of the Informant Questionnaire on Cognitive Decline in the Elderly (IQCODE): development and cross-validation. Psychol Med [Internet]. 2009/07/01.

1994;24:145-53. Available from: https://www.cambridge.org/core/article/short-form-of-theinformant-questionnaire-on-cognitive-decline-in-the-elderly-iqcode-development-andcrossvalidation/2724272682CB5E764C28AE7D49813332

29. Teresi J, Lawton M, Holmes D, M. O. Measurement in elderly chronic care populations. In: Morris J, Morris S, editors. ADL Assess Meas Use WithFrail Elders. New York, NY: Springer Publishing Co.; 1997. 
medRxiv preprint doi: https://doi.org/10.1101/2020.05.13.20100800; this version posted May 16, 2020. The copyright holder for this preprint (which was not certified by peer review) is the author/funder, who has granted medRxiv a license to display the preprint in perpetuity.

It is made available under a CC-BY-NC-ND 4.0 International license .

30. Ismail Z, Agüera-Ortiz L, Brodaty H, Cieslak A, Cummings J, Fischer CE, et al. The Mild Behavioral Impairment Checklist (MBI-C): A rating scale for neuropsychiatric symptoms in pre-dementia populations. J Alzheimers Dis [Internet]. 2017;56:929-38. Available from: http://www.ncbi.nlm.nih.gov/pmc/articles/PMC5652315/

31. Mallo SC, Ismail Z, Pereiro AX, Facal D, Lojo-Seoane C, Campos-Magdaleno M, et al. Assessing mild behavioral impairment with the mild behavioral impairment checklist in people with subjective cognitive decline. Int Psychogeriatrics [Internet]. 2018/07/18. 2018;19. Available from: https://www.cambridge.org/core/article/assessing-mild-behavioralimpairment-with-the-mild-behavioral-impairment-checklist-in-people-with-subjectivecognitive-decline/CB5EF7AD050C30ABB3BB7C5C1783B7A5

32. Mallo SC, Ismail Z, Pereiro AX, Facal D, Lojo-Seoane C, Campos-Magdaleno M, et al. Assessing Mild Behavioral Impairment with the Mild Behavioral Impairment-Checklist in People with Mild Cognitive Impairment. J Alzheimers Dis. 2018/09/04. Department of Developmental Psychology, University of Santiago de Compostela, Santiago, de Compostela, Galicia, Spain. Department of Psychiatry, University of Calgary, Calgary, Alberta, Canada. Department of Clinical Neurosciences, University of Calgary, ; 2018;66:8395.

33. Wise EA, Rosenberg PB, Lyketsos CG, Leoutsakos J-M. Time course of neuropsychiatric symptoms and cognitive diagnosis in National Alzheimer's Coordinating Centers volunteers. Alzheimer's Dement (Amsterdam, Netherlands). United States; 2019;11:333-9.

34. Lambert J-C, Ibrahim-Verbaas CA, Harold D, Naj AC, Sims R, Bellenguez C, et al. Metaanalysis of 74,046 individuals identifies 11 new susceptibility loci for Alzheimer's disease. Nat Genet [Internet]. 2013;45:1452-8. Available from: http://www.ncbi.nlm.nih.gov/pmc/articles/PMC3896259/

35. Euesden J, Lewis CM, O’Reilly PF. PRSice: Polygenic Risk Score software. 
medRxiv preprint doi: https://doi.org/10.1101/2020.05.13.20100800; this version posted May 16, 2020. The copyright holder for this preprint (which was not certified by peer review) is the author/funder, who has granted medRxiv a license to display the preprint in perpetuity.

It is made available under a CC-BY-NC-ND 4.0 International license .

Bioinformatics [Internet]. 2014;31:1466-8. Available from:

https://doi.org/10.1093/bioinformatics/btu848

36. Davies G, Armstrong N, Bis JC, Bressler J, Chouraki V, Giddaluru S, et al. Genetic contributions to variation in general cognitive function: a meta-analysis of genome-wide association studies in the CHARGE consortium (N=53ロ949). Mol Psychiatry [Internet]. 2015;20:183-92. Available from: https://doi.org/10.1038/mp.2014.188

37. Hill WD, Davies G, Group CCW, Liewald DC, McIntosh AM, Deary IJ. Age-Dependent Pleiotropy Between General Cognitive Function and Major Psychiatric Disorders. Biol Psychiatry [Internet]. 2015/09/04. Elsevier; 2016;80:266-73. Available from:

https://pubmed.ncbi.nlm.nih.gov/26476593

38. Donovan NJ, Amariglio RE, Zoller AS, Rudel RK, Gomez-Isla T, Blacker D, et al. Subjective cognitive concerns and neuropsychiatric predictors of progression to the early clinical stages of Alzheimer disease. Am J Geriatr Psychiatry. 2014/04/05. Center for Alzheimer Research and Treatment and Department of Neurology, Brigham and Women's Hospital, Harvard Medical School, Boston, MA; Department of Psychiatry, Brigham and Women's Hospital, Harvard Medical School, Boston, MA. Electronic address: njdo; 2014;22:1642-51.

39. Masters MC, Morris JC, Roe CM. "Noncognitive" symptoms of early Alzheimer disease: a longitudinal analysis. Neurology. 2015/01/16. 2015;84:617-22.

40. Geda YE, Schneider LS, Gitlin LN, Miller DS, Smith GS, Bell J, et al. Neuropsychiatric symptoms in Alzheimer's disease: past progress and anticipation of the future. Alzheimers Dement [Internet]. 2013/04/03. 2013;9:602-8. Available from:

https://pubmed.ncbi.nlm.nih.gov/23562430

41. Dietlin S, Soto M, Kiyasova V, Pueyo M, de Mauleon A, Delrieu J, et al. Neuropsychiatric Symptoms and Risk of Progression to Alzheimer's Disease Among Mild Cognitive Impairment Subjects. J Alzheimers Dis. 2019/05/28. Gerontopole, INSERM U 1027, 
medRxiv preprint doi: https://doi.org/10.1101/2020.05.13.20100800; this version posted May 16, 2020. The copyright holder for this preprint (which was not certified by peer review) is the author/funder, who has granted medRxiv a license to display the preprint in perpetuity.

It is made available under a CC-BY-NC-ND 4.0 International license .

Alzheimer's Disease Research and Clinical Center, Toulouse University Hospital, France. Institut de Recherches Internationales Servier, Suresnes, France.; 2019;

42. Ismail Z, Gatchel J, Bateman DR, Barcelos-Ferreira R, Cantillon M, Jaeger J, et al. Affective and emotional dysregulation as pre-dementia risk markers: exploring the mild behavioral impairment symptoms of depression, anxiety, irritability, and euphoria. Int Psychogeriatrics [Internet]. 2017/09/13. 2018;30:185-96. Available from: https://www.cambridge.org/core/article/affective-and-emotional-dysregulation-aspredementia-risk-markers-exploring-the-mild-behavioral-impairment-symptoms-ofdepression-anxiety-irritability-and-euphoria/0CDB9EABDFDF96915F5530602A6BBBFA

43. Savulich G, O’Brien JT, Sahakian BJ. Are neuropsychiatric symptoms modifiable risk factors for cognitive decline in Alzheimer's disease and vascular dementia? Br J Psychiatry [Internet]. 2019/04/30. Cambridge University Press; 2020;216:1-3. Available from: https://www.cambridge.org/core/article/are-neuropsychiatric-symptoms-modifiable-riskfactors-for-cognitive-decline-in-alzheimers-disease-and-vasculardementia/DE4291FEE2EFAB01C8DF95B7F0350614

44. Devi G, Scheltens P. Heterogeneity of Alzheimer's disease: consequence for drug trials? Alzheimers Res Ther [Internet]. 2018;10:122. Available from: https://doi.org/10.1186/s13195018-0455-y

45. Mortby ME, Black SE, Gauthier S, Miller D, Porsteinsson A, Smith EE, et al. Dementia clinical trial implications of mild behavioral impairment. Int Psychogeriatr. 2018/02/17. Centre for Research on Ageing,Health and Wellbeing,Research School of Population Health, The Australian National University,Canberra,Australia. Department of Medicine (Neurology),Hurvitz Brain Sciences Research Program,Sunnybrook Research Institute,Sunnybr; 2018;30:171-5. 